\title{
PARAPLEGIA FOLLOWING AORTIC SURGERY
}

\author{
By Chris Lynch, ${ }^{1}$ M.D. and Saul I. Weingarden, M.D. ${ }^{2}$ \\ ${ }^{1}$ Resident, and ${ }^{2}$ Associate Chief, Physical Medicine and Rehabilitation, \\ Santa Clara Valley Medical Center, 75I S. Bascom Avenue, San Fosé, California 95128
}

\begin{abstract}
It has long been recognised that paraplegia may occur after various surgical procedures on the heart and the aorta. Paraplegia occurring following traumatic rupture of the aorta has not been commonly reported due to the dismal prognosis of such rupture. Over the past 3 years, we have encountered five patients who survived traumatic rupture of the aorta and developed paraplegia, and three patients who had chronic dissecting aneurysms of the aorta who also developed paraplegia. These patients continued to show neurological and functional improvement over the years. We are presenting these cases to illustrate their neurological improvement and to show that the prognosis for these patients may not be as dismal as previously reported once they survive the acute episode.
\end{abstract}

\section{Introduction}

IT has long been recognised that paraplegia may occur after various surgical procedures of the heart and aorta (Watson, I979-80). Paraplegia following traumatic rupture and repair of the aorta has also been documented, but the prognosis has been poor, due to the complications of trauma (Gschaedler, 1978-79), or complications of surgical repair (Herendeen, I968). In a 3-year period, we have encountered five patients who sustained traumatic rupture of the aorta associated with paraplegia. These patients not only survived but have become independent in activities of daily living and have returned to work or school. In addition, gradual neurological improvement was noted over the ensuing years. The purposes of this paper are to suggest that the prognosis in such cases is not as dismal as previously reported (Gschaedler, I978-79), and to illustrate the progress these patients have made in their rehabilitation.

\section{Case Histories}

Case History I. This I4-year-old male youth was involved in a motor-cycle accident resulting in multiple trauma. At the scene of the accident his systolic blood pressure was $68 \mathrm{~mm} / \mathrm{Hg}$ and he was semi-responsive. Following resuscitation with intravenous fluids, his blood pressure became $150 / 80 \mathrm{~mm} \mathrm{Hg}$ and vital signs stabilised. On examination, there was an abraded area over the left anterior pectoral region and there was a faint bruit noted over the base of the left sternal border of the heart. The patient was stated to be able to move all four extremities. There was no further note of a more detailed neurological assessment. Chest X-ray showed an obviously wide mediastinum and an aortogram showed a tear of the descending thoracic aorta and he was immediately prepared for surgery. At surgery, the aorta was found to be totally transsected and bleeding was controlled with hand pressure and aortic clamp. A Dacron graft was inserted, and, during surgery, the patient developed rapid tachycardia resulting in asystole, and internal cardiac massage was undertaken. The patient responded to resuscitation and, following recovery from anaesthesia, he was found to have a Tio incomplete anterior spinal cord syndrome Frankel Class B. He was then referred to our institution and over the next 3 months he underwent intensive rehabilitation and demonstrated neuromuscular and functional improvement. At present, touch and pinprick 
are diminished below the level of the lesion by approximately 30 per cent, proprioception and vibration sense are normal. Motor power is grade 4 throughout both legs. Kneejerk reflexes are grade I/ 4 bilaterally, ankle jerks are absent bilaterally, and extensor plantar responses are present bilaterally. He has full control of bowel and bladder and full sexual function. He is now ambulating with long leg braces and has returned to school.

Case History 2. This I6-year-old male was involved in a motor-cycle accident in which he sustained multiple trauma. He had a fractured pelvis, fractured left femur, and fractured tibia. Initial vital signs showed a tachycardia of I I o beats/minute with a blood pressure of $60 \mathrm{~mm} \mathrm{Hg}$ systolic. Chest X-ray revealed a widened mediastinum. Immediate aortic arch study showed complete disruption of the aorta just beyond the left subclavian artery. Preoperatively, he was stated to be moving his legs but there was no neurological examination performed. At operation, there was free arterial blood in the left thorax, and complete transection of the arch of the aorta beyond the left subclavian artery was confirmed. Anastomosis was undertaken with Dacron and Teflon grafts. Postoperatively, the patient had many metabolic problems. Following recovery from anaesthesia, he was found to have a T6 complete spinal cord syndrome. Following medical and orthopaedic stabilisation, he was referred to our institution. Upon admission here, there was a T8 anterior spinal artery syndrome, Frankel Class C. He has now improved to a Frankel Class D, with grade 3-4 power present throughout the lower limbs. Pinprick and pain sensation are diminished but posterior column sensation is present. He is independent in wheelchair activities, and attends school but still has significant bladder and memory problems.

Case History 3. This is a 23-year-old male who was involved in an automobile accident. Initial vital signs were stable. Femoral pulses were diminished bilaterally. Chest X-ray showed a widened mediastinum. While en route for angiography for an aortagram, and before neurological assessment could be made, he suddenly became hypotensive and tachycardic and was immediately taken to the operating room with the suspected diagnosis of laceration of the aorta. At operation, a moderate amount of free blood was found in the left hemithorax, there was a small tear of the descending aorta just distal to the left subclavian. Upon recovery from anaesthesia he was found to have a TI2 Frankel Class C paraplegia. Following cardiovascular stabilisation he was transferred to our institution where he showed gradual neurological and functional improvement. When last seen here in 1978 he had improved to an $\mathrm{L}_{3}$ Frankel Class D paraplegia. He was independent in ADL skills, he was ambulating with the aid of short leg braces and he had normal bowel and bladder control.

Case History 4. This I 7-year-old male was injured in a motor vehicle accident in March I98I. He sustained the following injuries: ruptured left diaphragm and spleen and ruptured aorta, just distal to the left subclavian artery. On the day of injury, emergency splenectomy was performed and two days later, an aortagram revealed the above-mentioned thoracic aortic tear and on the same date, resection of the tear and insertion of a Dacron graft was performed. Postoperatively, it was noted that the patient had numbness and weakness in the legs. Myelography was performed and was normal. It is concluded that the patient sustained an ischemic myelopathy due to sacrifice of intercostal arteries during surgery. Following cardiovascular stabilisation, he was referred to this institution. Since that time, he has shown significant improvement. Hip movements are all 3-, knee flexion and extension 3-, ankles and feet grade $3+/ 5$. Vibration and position sense are normal. Pinprick sensation is diminished from $\mathrm{L}_{\mathrm{I}}$ through S5. Currently, the patient is doing very well, and is now able to walk almost unlimited distances in the parallel bars without any bracing and without assistance. He is now beginning to void spontaneously and is improving in all parameters.

Case History 5. This is an I8-year-old male who was involved in a motor vehicle accident in December I980. He sustained multiple injuries including an open com- 
minuted fracture of the right femur, open fracture of the right proximal tibia with destruction of the medial collateral anterior cruciate and posterior capsular structures of the right knee, fracture of the right tibia, comminuted closed fracture of the left femur, fracture of the pelvis, rupture of bladder and bladder neck, and complex lacerations extending from the left upper lip and the nose to the right superior axilla. Four days after the accident and following multiple orthopaedic procedures, a murmur was appreciated and following aortography, this proved to be a tear of the thoracic aorta in its descending portion. This tear was repaired by a Dacron graft. Postoperatively the patient developed an anterior spinal artery syndrome together with respiratory distress, diabetes insipidus, and infection of the right knee joint. Following stabilisation from these multiple medical and surgical problems, the patient was referred to our institution for rehabilitation. Sensory examination of the lower extremities revealed impaired sensation to all modalities below the knees, proximal muscles in both hips were grade $2 / 5$ with quadriceps bilaterally grade 2 and hamstrings I + bilaterally. He had no movement below the knees. Reflexes in the upper extremities were normal. Knee jerks were present but hypoactive bilaterally. Ankle jerks and plantar responses were absent bilaterally. We felt that the diagnosis was compatible with an anterior spinal artery syndrome combined with severe peripheral nerve damage caused by multiple compound fractures. This patient is presently in our hospital and continues to improve in functional abilities but due to the gross damage to his peripheral nerves in the lower extremities, neurological recovery has been limited.

Case History 6. This is a $5 \mathrm{I}$-year-old male with a well-documented chronic dissection of a thoracic aortic aneurysm. Initial aortagram in June 1978 confirmed the diagnosis of dissection of the aorta and at that time, the aorta was oversewn. Four months later, the descending aorta was replaced. Both these operations went without incident. Six months after the initial surgery, the patient was reoperated on for repair of a small portion of the descending thoracic aorta. Following anaesthetic recovery, the patient was observed to be able to move both legs. Within several hours of the third operation, he developed acute hypotension and tachycardia and a distended abdomen. Immediate laparotomy was performed and rupture of an abnormal spleen was found. Pathological examination of the spleen revealed mononucleosis. This was later confirmed by appropriate blood tests. Following this operation, the patient was noted to have a T6 incomplete Frankel Class C anterior spinal artery syndrome. Currently, the patient is ambulating with bilateral ankle foot orthoses and Canadian crutches, and is independent for all activities of daily living. Bladder, bowel and sexual activities have returned to normal. Motor power above the hip joint is $4+/ 5$. Motor power about the knee joint is grade $4+$ in knee extension and grade $3+$ in knee flexion. Ankle flexors and extensors are grade 4 bilaterally. Position and vibration sense are normal. The patient is able to walk without the aid of these appliances but fatigues easily without them.

Case History 7. This 56-year-old white male developed anterior chest pain and epigastric pain in October 1980. He was subsequently evaluated in a coronary care unit and a discrepancy in the femoral pulses was noted in addition to a bruit heard in the posterior midline. An aortagram revealed a type $\mathrm{B}$ dissection of the descending thoracic aorta. He soon became asymptomatic and it was decided at that time to treat him medically with intravenous hypotensive agents. Approximately I month later, he developed recurrent pain, and aortography and CT scan revealed a definite intimal flap in the distal portion of the descending aorta. Three days later he had a left thoracotomy, and the proximal portion of the descending thoracic aorta was replaced with a $30 \mathrm{~mm}$ low velocity Dacron graft. The patient had a benign perioperative period, remaining normotensive on low doses of nitroprusside and his cardiac status remained stable. Following extubation, neurological examination revealed weakness of the lower extremities and findings consistent with an anterior spinal artery syndrome with early loss of dorsal column sensation. In addition, the patient was considerably hoarse and this was felt to be compatible with involvement of the left recurrent laryngeal nerve which was 
dissected free from the aorta and its ligament at the time of surgery. Following cardiovascular stabilisation, he was referred to this hospital for rehabilitation. The hip flexors bilaterally were grade $3+/ 5$, hip extensors grade $4 / 5$, knee flexors grade $4 / 5$, knee extensors grade $4 / 5$. Ankle plantar flexors were grade $4 / 5$ and ankle dorsiflexors grade $4 / 5$. There was a sensory level at the level of the umbilicus. Fine touch and pinprick were diminished but present throughout below this. Vibration sense and proprioception were intact throughout. Reflexes; both knee jerks grade $2+/ 4$, ankle jerks grade $2+/ 4$, and plantar responses flexor. Following a relatively short period of rehabilitation, this patient has improved to the extent that he is able to walk approximately half a mile without assistive devices. $\mathrm{He}$ is urinating normally. Sexual function has returned. $\mathrm{He}$ is being followed up at this clinic and shows continued improvement.

Case History 8. This is a 70-year old male who had a long history of arterial claudication. Aortography revealed occlusion of the left common iliac artery at its origin, and also high grade stenosis of the right iliac artery at its origin with bilateral popliteal disease. The patient was treated with an aortal femoral resection and insertion of Dacron graft. No intraoperative difficulties were noted. Following recovery from the anaesthetic, neurological examination showed decreased sensation from approximately $\mathrm{L}_{2}$ on the left to $\mathrm{S}_{3}$. Light touch, pin and temperature sensation were diminished in this distribution also. Position sense was absent in toes, ankle and knee on the left and absent in the right leg. Vibration sense was absent up to the iliac crest on the left and absent to the knee on the right. Deep tendon reflexes; knee jerks $\mathrm{O} / \mathrm{I}$, hamstrings $\mathrm{O} / \mathrm{I}$, achilles $\mathrm{O}$. Clinical impression is of probable spinal cord infarction secondary to vascular insufficiency, at approximately $\mathrm{L}_{3}$. The patient was then transferred to our institution where he received long-term rehabilitation and improved to the state where he is able to ambulate with the assistance of a left double upright ankle foot orthosis on the left. $\mathrm{He}$ continues to be followed up at this clinic and though he has only shown minimal improvement, he is now functionally independent.

\section{Discussion}

The prognosis of paraplegia associated with traumatic rupture of the aorta has been reported to be dismal. Gschaedler et al. report a mortality figure of roo per cent in their cases of paraplegia associated with traumatic rupture of the aorta (1978-79). In another review by Herenden and King, 30 cases of early repair of traumatic rupture of the thoracic aorta were reviewed (I968). Of these, there is only one in which paraplegia was part of the presenting picture. In three others, paraplegia was mentioned, but these patients died during a subsequent operation. There have been other isolated case reports by Hughes (I964), Heroy (I96I) and deMuth et al. (1965). The pathophysiology of spinal cord injury and cardiovascular surgery has been well reviewed by Watson (1979-80) and Grace and Mattox (1977). In Watson's case reports, of four patients, two patients had coarctation of the aorta, one patient had a traumatic aortic aneurysm and one patient had the tetralogy of Fallot. All these cases developed the anterior spinal artery syndrome. Grace and Mattox (1977) reported a similar case of anterior spinal artery syndrome following abdominal aortic aneurysectomy. They reviewed 28 cases in the literature of spinal cord ischaemia following abdominal aortic aneurysectomy. Of these patients, only seven showed neurological improvement over a period of 6 years.

In our series of five patients who developed paraplegia following traumatic aortic rupture, all showed signs of anterior spinal artery syndrome. All demonstrated significant neurological improvement, with return of motor, sensory, and reflex activity below the level of the lesion. This improvement has also been 
reflected in the level of independence. Four of the five are walking without the aid of orthotic devices and the same number have normal control of bowel and bladder. These patients developed their paraplegia in a 3-year period and they have all now returned either to work or to school. We would agree with Grace and Mattox (1977) that a significant recovery of neurological function following spinal ischaemia after aortic surgery does occur, but is unpredictable. However, this clustering of five cases of survival and return to independent functional activities following paraplegia associated with traumatic rupture of the aorta, indicates that the prognosis may not be as hopeless as previously thought, provided they survive the acute episode. These case reports emphasise that while paraplegia may be associated with traumatic rupture of the aorta, early surgical repair and vigorous supportive therapy are indeed indicated at all stages, as neurological improvement may occur over an extended period of time.

Acknowledgment. We would like to thank Kathie Kelly for her continued assistance and support in the preparation of these papers.

\section{SUMMARY}

Case histories of five survivors of traumatic rupture of the aorta and three patients with chronic aortic dissection are presented. All patients became paraplegic as a result of vascular insufficiency but demonstrated varying degrees of neurological and functional improvement.

\section{RÉSUMÉ}

Cinq survivants de rupture traumatique de l'aorte et trois de dissection chronique sont presentés dans cet article. Tous les huit sont devenus paraplégiques à la suite de l'événement vasculaire mais presentent différents niveaux de récuperation neurologique et fonctionnelle.

\section{ZUSAMMENFASSUNG}

Fünf Überlebende nach gewaltsamen Reissen der Aorta und drei Patienten mit Paraplegie nach Operationen an der Aorta werden vorgestellt. Alle diese Patienten entwickelten Paraplegie wegen Durchblutungsstörungen, aber alle zeigten verschiedene Grade der neurologischen und funktionellen Besserung.

\section{REFERENCES}

Grace, R. \& MATtox, K. (1977). Anterior spinal artery syndrome following abdominal aortic aneurysectomy. Arch. Surg., 112, 813-815.

Gschaedler, R., Dollfus, P., Loeb, J. P., Mole, J. P., Huber, B. \& Adli, G. (1978-79). Traumatic rupture of the aorta and paraplegia. Paraplegia, 16, 123-127.

HERENDEN, T. L. \& KING, H. (I968). Transient anuria and paraplegia following traumatic rupture of the thoracic aorta. F. Thor. Card. Surg., 56, 599-602.

Heroy, W. W. (196I). Discussion of meeting papers. F. Thor. Card. Surg., 4r.

Hughes, J. T. (I964). Spinal cord infarction due to aortic trauma. Brit. Med. F., 2, 356.

DeMuth, W., RoE, H. \& HobBIE, W. (I965). Immediate repair of traumatic rupture of the thoracic aorta. Arch. Surg., 91, 602.

Watson, N. (1979-80). Paraplegia following cardiovascular surgery. Paraplegia, 17, 294-297. 